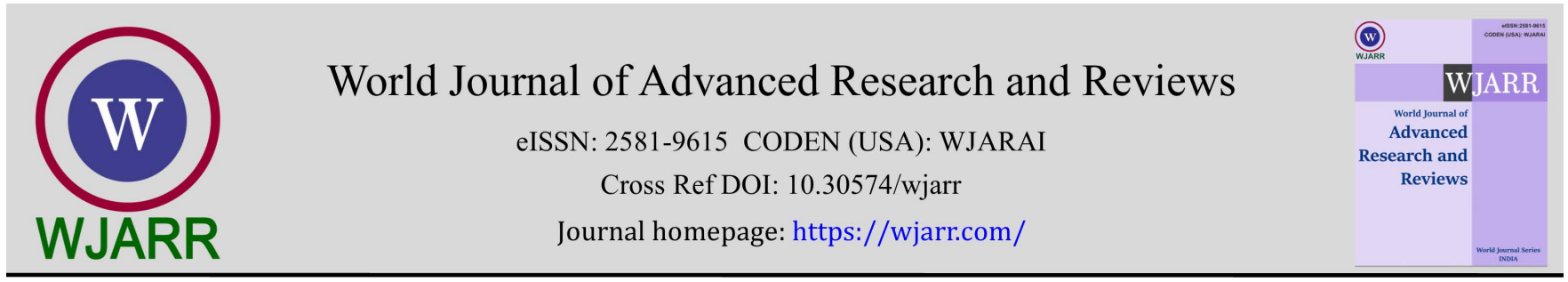

(RESEARCH ARTiCle)

Check for updates

\title{
Diagnosis of fasciolosis in cattle slaughtered at the slaughterhouse of the urban commune of Dédougou in Burkina Faso
}

\author{
Modou Séré 1, *, Micheline Nomtondo Sawadogo 1, Sié Hermann Pooda 1, Benoît Kaboré 2, Adama Kaboré 3 , \\ Hamidou Hamadou Tamboura ${ }^{3}$ and Adrien Marie Gaston Belem ${ }^{4}$ \\ ${ }^{1}$ Institute of Environmental Sciences and Rural Development/University of Dédougou. ISEDR/UDDG, P.O. Box 176, \\ Dédougou, Burkina Faso. \\ 2 Provincial Directorate of Animal and Fishery Resources/Regional Directorate of Animal and Fishery Resources of the \\ Boucle du Mouhoun, Burkin Faso. \\ ${ }^{3}$ Laboratory of Biology and Animal Health/Institute of Environment and Agricultural Research of Burkina Faso. INERA / \\ CNRST, P.O. Box 03-7192, Ouagadougou 03, Burkina Faso. \\ ${ }^{4}$ Institute of Rural Development/University of Nazi Boni. IDR/UNB, P.O. Box 01-1091 Bobo-Dioulasso 01, Burkina Faso.
}

World Journal of Advanced Research and Reviews, 2021, 12(03), 497-504

Publication history: Received on 16 October 2021; revised on 20 December 2021; accepted on 25 December 2021

Article DOI: https://doi.org/10.30574/wjarr.2021.12.3.0716

\begin{abstract}
Fasciolosis is a major zoonosis of ruminants which causes great economic losses to breeders. Given the economic and public health importance of this pathology, it is necessary to establish the current situation in a perspective of animal and ruminant meat consumer health protection. Therefore, the present study was conducted at the slaughterhouse of Dédougou in order to identify the species of fluke that caused this pathology in the Boucle du Mouhoun region and to estimate the prevalence, the risk factors and the economic losses associated with this pathology. For this purpose, 820 cattle and 6360 small ruminants were diagnosed through post-mortem examination over a five-month period from March to August 2018. Out of the 6360 small ruminant livers examined, no cases of infestation were observed unlike cattle in which the prevalence of infestation was $2.07 \%$. These infestations were all due to Fasciola gigantica. Regarding the risk factors, a slight effect of the month and a high influence of animals' origin were observed. March, with a prevalence of $0.25 \%$, was the most favorable infestation month $(P$-value $=0.05)$ and Sourou $(19.51 \%)$, was the highest infestation risk area $(P$-value<0.0001). The estimated financial loss associated with the infestations was XOF $22,200.29$ per infested animal. The situation is particularly worrying insofar as some populations, especially rural populations, consume meat from uncontrolled slaughter areas. Appropriate precautions should therefore be taken to ensure both consumer and animal health, given the zoonotic nature of the disease.
\end{abstract}

Keywords: Fasciolosis; Ruminants; Fasciola gigantica; Slaughterhouse; Dédougou

\section{Introduction}

Ruminant fasciolosis is a cosmopolitan and zoonotic parasitic disease [1] due to the invasion of the liver and bile ducts by trematodes of the genus Fasciola, also known as flukes. The most known Fasciola species causing this pathology in ruminants of the local livestocks are Fasciola hepatica and Fasciola gigantica. The first species is found mainly in temperate areas while the second is a fluke of tropical and subtropical countries. In Africa, Fasciola gigantica is the most common species, transmitted to animals by mollusks of the genus Lymnea [2].

\footnotetext{
${ }^{*}$ Corresponding author: SERE Modou

Institute of Environmental Sciences and Rural Development/University of Dédougou. ISEDR/UDDG, P.O. Box 176, Dédougou, Burkina Faso.
}

Copyright $(2021$ Author(s) retain the copyright of this article. This article is published under the terms of the Creative Commons Attribution Liscense 4.0. 
In ruminants, this pathology incurs additional treatment costs and affects the growth, the survival, the fertility, and the milk and meat production, resulting in large economic losses for livestock producers [3].These losses are estimated to be $\$ 2$ million or XOF 1,166,100,000 per year worldwide [4]. In Africa this pathology has been the subject of several studies showing that its incidence varies greatly on the one hand between study areas $[5,6,7]$ and on the other hand between countries $[8,9,10,11]$.

In Burkina Faso, the frequency of this disease is still not well known in some regions such as the Boucle du Mouhoun region, although research results tend to show a high variance of prevalence at national [12] and regional[13]levels. Given the economic importance of this disease and its zoonotic nature, existing data need to be updated in order to establish the current situation and to reassure consumers of ruminant meat. The present study was therefore conducted in the slaughterhouse of the urban commune of Dédougou in the Boucle du Mouhoun region of Burkina Faso in order to identify the responsible fluke species and to estimate the prevalence, the risk factors and the economic losses associated with this pathology among the butchers of the commune.

\section{Material and methods}

\subsection{Study area}

The present study was conducted at the communal refrigerated slaughterhouse of Dédougou located in the east of this city at about five $\mathrm{km}$ from the city center. Dédougou is the chief town of the Boucle du Mouhoun region, which is located in northwestern Burkina Faso between latitude $12^{\circ} 30^{\prime}$ North and longitude $3^{\circ} 30^{\prime}$ West [14] and covers an area of 34,145 $\mathrm{km}^{2}$, representing $12.59 \%$ of the national territory.

\subsection{Animal samples and ante mortem examination}

The biological material used in this study included 820 cattle and 6360 small ruminants slaughtered at the Dédougou slaughterhouse. Before their slaughter, each ruminant was carefully identified and the informations on species, breed, sex, provenance, age and selling reason were recorded. For animals' age, two groups were considered ( $\geq 2$ and $<2$ ). Age determination was carried out based on the dental table. The other data were obtained from the butchers after a short interview.

\subsection{Post mortem examination and liver flukes characterization}

Flukes were detected as part of the systematic inspection of meat produced by slaughterhouses in collaboration with the veterinary agents of the Dédougou provincial livestock directorate. For this purpose, an inspection of the liver based on visual observation, palpation and standard incisions was performed. Animals were considered as infested by the genus Fasciola when living or calcified flukes were found in the large bile ducts. Fluke's species were then determined based on adult size [15]. Thus, the criterion of species determination was the following:

- When the fluke length was included 2 to $3 \mathrm{~cm}$ with a width of about $1 \mathrm{~cm}$, these have been classified into Fasciola hepatica species;

- $\quad$ and those which length was included $2,5 \mathrm{~cm}$ to $7.5 \mathrm{~cm}$ with a width of $1.5 \mathrm{~cm}$ have been classified into Fasciola gigantica species.

\subsection{Data analysis}

The collected data were entered into a database using Excel 2013 software. The number of parasitized animals was used to estimate the prevalence according to equation 1. This number was also compared between the modalities of the different explanatory variables (species, season, month, breed and sex) using the R software. For this purpose, Fisher's exact test was used and comparisons were based on the $5 \%$ significance level.

$$
\text { Prevalence }=\frac{\text { Number of infested cattle }}{\text { Number of inspected cattle }} \times 100 \quad \text { (Equation 1) }
$$

To correct the effect of repeated test, as is the case when comparisons are made between pairs of parameters, the method of Benjamini and Yekutieli [16] using the "p. adjust" function of the R software was used.

Economic losses due to fasciolosis were estimated based on losses related to liver condemnation and carcass weight losses. Thus, losses from cattle liver condemnation were estimated using Equation 2 based on the formula in Elmonir et al. [17]. 
Where EL_liver is the economic loss due to liver condemnation, $N_{-}$liver is the number of condemned livers and $C_{-}$liver is the average cost of the liver according to the information provided by the butchers.

Economic losses due to carcass weight losses were estimated using Equation 3 in accordance with Swai and Ulicky [18].

$$
\left.E L \_ \text {carcass }=N \_ \text {animal } \times\left(C \_ \text {carcass } * 10 \%\right) * \text { Prev } \quad \text { (Equation } 3\right)
$$

Where EL_carcass is the economic loss due to carcass weight loss, $N$ _animal is the number of animals slaughtered during the study, $C_{-}$carcass is the average carcass cost and Prev is the prevalence of fasciolosis during the study.

Total losses due to fasciolosis were estimated as the sum of El_liver and EL-Carcass and all the economic losses were estimated in XOF currency.

\section{Results}

\subsection{Prevalence}

Among the 820 cattle inspected during the study, 17 were infested with flukes, corresponding to a prevalence of $2.07 \%$. However, we did not obtain any cases of fasciolosis in small ruminants. All adult flukes found belonged to the Fasciola gigantica species regarding adults' sizes.

\subsection{Effects of studied risk factors}

\subsubsection{The Race}

During the study, two main cattle breeds were found, the taurine and zebu, and probably half-breeds from these two breeds which were affected to one or other depending on the dominant feature (presence or absence of hump). Only humped cattle were infested with flukes of the genus Fasciola with a prevalence of $2.11 \%$ (Table 1). The limited number of taurine cattle did not provide any relevant inference about breed impact. Nevertheless, statistical analysis revealed that the observed difference was not significant $(P$-value $=1)$.

Table 1 Prevalence of fasciolosis by breed of inspected cattle

\begin{tabular}{|l|c|c|c|c|}
\hline Breeds & Number of inspected cattle & Number of infested cattle & Prevalence (\%) & $\boldsymbol{P}$-value \\
\hline Taurine & 15 & 0 & 0 & \multirow{2}{*}{1} \\
\hline Zebu & 805 & 17 & 2.11 & \\
\hline
\end{tabular}

\subsubsection{Animals' age}

The prevalence of infestation was relatively high in animals older than two years old (2.28\%) compared to younger ones (0.68). However the observed difference was not significant ( $P$-value=0.3331) (Table 2).

Table 2 Fasciolosis prevalence according to inspected cattle age

\begin{tabular}{|c|c|c|c|c|}
\hline Age & Number of inspected cattle & Number of infested cattle & Prevalence (\%) & \multirow{P}{*}{-value } \\
\hline$\leq 2$ & 147 & 1 & 0.68 & \multirow{2}{*}{0.3331} \\
\hline$>2$ & 673 & 16 & 2.38 & \\
\hline
\end{tabular}

\subsubsection{The Period/month}

The highest infestation rates were obtained during March (6.25\%) followed by July (2.89\%) and April (2.76\%). However, although a significant number of cattle were inspected in August, no cases of fluke infestation were observed during this month (Figure 1). 


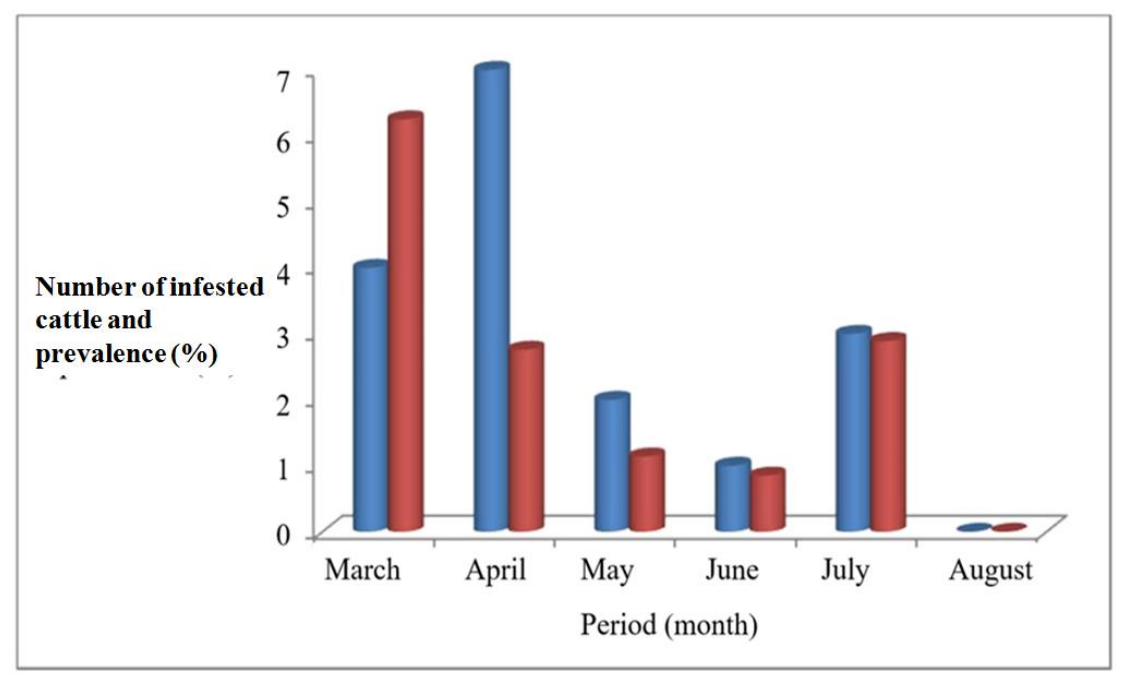

Figure 1 Number of infested cattle (blue) and prevalence (red) according to the month of study

Pairwise comparisons (Table 3) showed that the difference of the infested animals number was significant between March and August $(P$-value $=0.019)$ and marginally significant between March and June $(P$-value $=0.054)$. However, after correction, none of these differences remained significant, as the smallest $P$-value $(0.01937)$ became $P$-value $=0.2055$, thus not significant.

Table 3 Pairwise $P$-values resulting from comparisons between infestation months

\begin{tabular}{|l|c|c|c|c|c|c|c|c|}
\hline Month & N-insp & N-inf & Prevalence & March & April & May & June & July \\
\hline March & 64 & 04 & 6.25 & 0 & & & & \\
\hline April & 254 & 07 & 2.76 & 0.241 & 0 & & & \\
\hline May & 176 & 02 & 1.14 & 0.045 & 0.320 & 0 & & \\
\hline June & 117 & 01 & 0.85 & 0.054 & 0.444 & 1 & 0 & \\
\hline July & 104 & 03 & 2.89 & 0.429 & 1 & 0.364 & 0.345 & 0 \\
\hline August & 105 & 0 & 0 & 0.019 & 0.111 & 0.530 & 1 & 0.498 \\
\hline
\end{tabular}

$\mathrm{N}$-insp is the number of inspected cattle, $\mathrm{N}$-inf is the number of infested cattle. The $P$-values of comparison between pairs of months are presented as a half matrix on the right hand side of the table.

\subsubsection{The Period/season}

The results of season's effect on slaughtered and inspected cattle infestation are shown in Table 4. We observed that the dry season is more susceptible to fluke infestation (2.63\%) compared to the rainy season $(1.23 \%)$. However, the observed difference remained insignificant $(P$-value $=0.213)$.

Table 4 Prevalence of fasciolosis according to the season

\begin{tabular}{|l|c|c|c|c|}
\hline Season & Number of inspected cattle & Number of infested cattle & Prevalence (\%) & $\boldsymbol{P}$-value \\
\hline Rainy season & 326 & 4 & 1.23 & \multirow{2}{*}{0.213} \\
\hline Dry season & 494 & 13 & 2.63 & \\
\hline
\end{tabular}

\subsubsection{The animal's sex}

The prevalence of fasciolosis in male cattle was $2.12 \%$ compared to $2.05 \%$ in females (Table 5). These prevalences are almost identical suggesting that the animal's sex has no significant effect $(P$-value $>0.05)$ on Fasciola gigantica infestation in the examined cattle. 
Table 5 Prevalence of fasciolosis according to examined cattle sex

\begin{tabular}{|l|c|c|c|c|}
\hline Season & Number of inspected cattle & Number of infested cattle & Prevalence (\%) & $P$-value \\
\hline Male & 283 & 6 & 2.12 & \multirow{2}{*}{1} \\
\hline Female & 537 & 11 & 2.05 & \\
\hline
\end{tabular}

\subsubsection{Selling motive}

The different selling motive of cattle slaughtered at the Dédougou slaughterhouse are reported in Table 6. It is apparent that these motives do not significantly affect animal infestation rates ( $P$-value $>0.05)$. It also appears that $35.9 \%$ of the cattle brought to the Dédougou slaughterhouse for slaughter were diseased animals and that $1.7 \%$ of these animals were infected with Fasciola gigantica. Thus, only 5 out of 17 or $29.41 \%$ of the animals diagnosed as positive presented a sickly state.

Table 6 Prevalence of fasciolosis according to selling motives

\begin{tabular}{|l|c|c|c|c|}
\hline Selling motive & Number of inspected cattle & Number of infested cattle & Prevalence (\%) & $P$-value \\
\hline Feed & 5 & 0 & 0 \\
\hline Silver & 227 & 5 & 2.2 \\
\hline Schooling & 15 & 1 & 0.067 \\
\hline Fracture & 73 & 0 & 0 \\
\hline Disease & 294 & 5 & 0.017 \\
\hline Food problem & 205 & 6 & 0.0293 \\
\hline Family problem & 1 & 0 & 0 \\
\hline
\end{tabular}

\subsubsection{Animal's origin}

The animals slaughtered at the Dédougou slaughterhouse came mainly from the Boucle du Mouhoun region and specifically from the provinces of Mouhoun (93.5\%), Banwa (1.5\%) and Sourou (5\%) (Table 7). At first glance, animals from Sourou with the prevalence of $19.51 \%$, seem to be most infested, especially compared to animals from Mouhoun province $(P$-value $<0.0001$ even after correction). The number of animals slaughtered at the abattoir from the province of Banwa was relatively low (12 animals). This did not allow an adequate analysis of the animals' infestation level in this locality, especially compared to the two other provinces.

Table 7 Pairwise P-values resulting from comparisons between the animals' origin provinces

\begin{tabular}{|l|c|c|c|c|l|}
\hline Provenances & N-insp & N-inf & Prevalence & Banwa & $\begin{array}{l}\text { Mouhou } \\
\text { n }\end{array}$ \\
\hline Banwa & 012 & 00 & 00 & & \\
\hline Mouhoun & 767 & 09 & 1.17 & 1 & \\
\hline Sourou & 041 & 08 & 19.51 & 0.1748 & $3.81 \mathrm{e}-7$ \\
\hline
\end{tabular}

The number of inspected cattle ( $\mathrm{N}$-insp) and infested cattle ( $\mathrm{N}$-inf) are given. The P-values for comparison between pairs of provinces are presented in matrix form on the right-hand side of the table.

\subsubsection{Organ condemnation and economic losses}

The organ condemnation concerned the livers of the infested animals. A total of 17 infected livers were seized. The average cost of the liver according to information collected from butchers was XOF 7,637 leading to a loss of XOF 129,824 due to seizures of livers. In addition, indirect losses due to carcass weight losses amounted to XOF 247,581 leading to a total loss of XOF 377,405 due to fasciolosis during the six months of the study.

\section{Discussions}

\subsection{Prevalence study}


The prevalence of fasciolosis in cattle slaughtered at Dédougou slaughterhouse was 2.07\%. This prevalence is higher than the prevalence of $0.82 \%$ and $1.72 \%$ observed respectively by Dahourou et al., [11] at Ouagadougou in Burkina Faso and Youssef and Uga [10] in Egypt. The prevalence obtained in the present study is nevertheless in a same order of magnitude as the prevalence of $2.2 \%$ observed in a study conducted in Iran by Khanjari et al. [19]. However, the present prevalence is lower than the prevalence of 8\% reported in Nigeria [9] and Kenya [5]. It is also lower than the prevalence of 21.8\% reported by Ardo et al. [7] in Adamawa State at Nigeria. The observed differences can be explained not only by the level of animals' resistance but also by the farming conditions. These differences can also be explained by the differences between climates of the study areas. Indeed, climate plays a major role in the development of the fluke life cycle [5].

\subsection{Risk factors}

The infested cattle were all zebus. No study in our knowledge has explored the effect of breed on fluke infestation. Nevertheless, taurine cattle are known to be very hardy animals. They are furthermore known to be tolerant or resistant to trypanosomes [20]. Genetic factors could therefore explain our results, but the small number of animals of this breed in the present study (15 taurine) is a limitation to this interpretation. However, the genetic difference between cattle and small ruminants has been suspected as a factor that could explain susceptibility to fasciolosis in some studies [9, 11]. According to these authors small ruminants are more resistant to fasciolosis. This resistance could further explain the $0 \%$ prevalence found during the present study in small ruminants. The null prevalence in small ruminants can also be explained by the difference in the breeding methods of these animals

Our results showed that the prevalence of fascilosis was $0.68 \%$ in cattle less than or equal to 2 years old and $2.38 \%$ in cattle older than 2 years. These results are similar to those of Zagare [12], Pangui et al [21], Kithuka et al [5] and Ardo et al [7]. These observations can be explained by the fact that at less than 2 years old, young cattle are just starting to frequent infested pastures and do not make long movements, thus explaining the low rate obtained for this age group. Adults and animals over 4 years old, given their transhumance during the dry season, are likely to be infested because of their concentration on grazing areas and watering holes.

In the overall, the month did not present a significant influence on fasciolosis transmission in our study, thus nuancing the results of Mazedul et al[22] who recorded a high prevalence in July (5.6\%). However, this prevalence is lower than the one recorded in March (6.25\%) in the present study. March is therefore likely to be the most critical period of the year in terms of cattle infestation by flukes in the Boucle du Mouhoun region. Indeed, during this month, the Mouhoun River and the Sourou Dam are points of attraction for animals for their feeding and watering. The animals are strongly concentrated around these water points, thus increasing their infestation risk. This also explains the relatively high prevalence in the hot dry season (2.63\%) compared to the rainy season $(1.23 \%)$. These results corroborate those of Koyee et al (Cited by Mazedul et al., [22]) who found a prevalence of $4.61 \%$ in the dry season compared to $3.88 \%$ in the rainy season.

Regarding the effect of cattle sex on infestation risk, no significant difference was observed between males (2.12\%) and females (2.05\%) in our study. This finding is similar to that of Mazedul et al. [22] who found a prevalence of 3.79\% for males and 3.85\% for females. However, this result nuances those of Zagare, [12] who believe that females for multiple reasons especially physiological, gestation and Breastfeeding, are the preferred target of parasitic diseases including faciolosis. The result on the effect of sex in the present study also differs from those of Ardo et al[7] in Nigeria who found that females are significantly affected compared to males.With regard to the animals selling reason, those stated by the butchers during the interviews did not show significant influences on the prevalence of fasciolosis. A significant impact of the disease, as a reason for the animals' departure from farms, was expected on the prevalence of the slaughtered cattle infestation. This would suggest that animals are regularly treated against parasites.

In the present work, we found a variance in the prevalence of Fasciola gigantica fasciolosis between the provinces of origin of the animals. Our results showed that Sourou is the most affected province followed by Mouhoun province. The variance in results between provinces has already been mentioned by Zagare [12] in Burkina Faso. A difference in prevalence rate between different localities has also been observed in Kenya [5] (Kithuka et al., 2002) and Upper Egypt [6]. This variance is probably due to the variation in the ecological environment that conditions the survival of intermediate hosts. The higher prevalence observed in the Sourou province is in contrast to the $0 \%$ prevalence found in this locality by Zagare [12]. These observations may be due to the high animal densities caused by the absence of tsetse flies and the decline of animal trypanosomiasis in the province. Herders who once avoided the waterside areas to minimize the risk of infection from trypanosomiasis now roam all the grazing areas in the province.

\subsection{Economic Losses}


In terms of economic losses, a total of 17 cattle livers were seized with an average cost of XOF 7637 per liver. Combined with the loss of carcass weight due to the infestation, the economic loss per diseased animal was XOF 22,200.29. This loss is not negligible for the affected butchers. An overall loss of XOF 141,789,575 was found for the Ouagadougou slaughterhouse over a six-year period (2007-2013) [11]. Relatively high annual economic losses, XOF 164,285,091 (considering the exchange rate of $549.75 \mathrm{XOF}=1$ dollar (US)) were also observed in Kenya [5]. The differences are probably related to sample size and slaughterhouse capacity. In our study, the loss was estimated over a period of six months and only 820 cattle were inspected. On the other hand, a substantial portion of the animals from the Boucle du Mouhoun region is exported to areas with a high level of meat demand, notably the Hauts Bassins region.

\section{Conclusion}

Our study on the epidemiology of ruminant fasciolosis was carried out at the slaughterhouse in the urban commune of Dédougou. This study allowed an overview of this pathology in this locality of Burkina Faso. The study showed that Fasciola gigantica is the pathogen responsible to cattle fasciolosis in the Boucle du Mouhoun region. No cases of infestation were detected in small ruminants. The study also revealed that breed, sex, animals selling reason, season did not have a significant influence on the disease. However, the origin of the animals and probably the month of the year influence the infestation of Fasciola gigantica fasciolosis in slaughtered and inspected cattle at the refrigerated slaughterhouse of Dédougou. We also found that this pathology causes considerable economic losses to the butchers of the said slaughterhouse. However, the post mortem diagnostic method used in this study determines the prevalence of infestations in real time. This method is not very sensitive and does not take into account animals that have recovered after treatment. Therefore, the prevalences were probably underestimated. Further study using more sensitive methods such as coprology and in vivo tests is needed to support our results notably in Mouhoun and Sourou areas. Given the observed prevalences, the communal and health authorities should undertake awareness campaigns to limit clandestine slaughters and encourage breeders to protect their animals against this disease.

\section{Compliance with ethical standards}

\section{Acknowledgments}

The authors of the study thank the Regional Directorate of Animal and Fishery Resources of the Boucle du Mouhoun through its Provincial Directorate and the butchers of the Dédougou urban commune slaughterhouse for their generous collaboration.

\section{Authors' contributions}

The contributions of the various authors were as follows:

- Modou Séré, Assistant Professor at the University of Dédougou, contributed to the design of the study and the writing of this article;

- Micheline Nomtondo Sawadogo, a student at the end of her engineering studies, contributed to the collection of data and the writing of this article;

- Hermann Sié Pooda Assistant Professor at the University of Dédougou contributed to the design of the study and the writing of this article

- Benoît Kaboré, Livestock Technician, contributed to the collection of data and the writing of this article;

- Adama Kaboré, Director of Research contributed to the design of the study, the writing of this article and the supervision of the work;

- Hamidou Hamadou Tamboura, Director of Research contributed to the design of the study, the writing of this article and the supervision of the work;

- Adrien Marie Gaston Belem, Professor at the University of Nazi Boni of Bobo-Dioulasso contributed to the design of the study, the writing of this article and the supervision of the work.

\section{Disclosure of conflict of interest}

The authors declare that there is no conflict of interest. 


\section{References}

[1] Soulsby, EJL. Helminths, arthropods and protozoa of domesticated animals. 6th ed. London: Bailliere \& Tindall; 1986.

[2] Losos GJ. Infectious Tropical Disease of Domestic Animals, 1st ed. New York : Longman Scientific and Technical; 1995. p. 851-894.

[3] Gracey FJ, Collins DS. Meat hygiene, 9th ed. London: Bailliere \& Tindall; 1992.

[4] Torgerson P, Claxton J. Epidemiology and control. Fasciolosis. 1999; 113: 149.

[5] Kithuka JM, Maingi N, Njeruh FM, Ombui JN. The prevalence and economic importance of bovine fasciolosis in Kenya-an analysis of abattoir data. Onderstepoort Journal of Veterinary Research. 2002; 69:255-262.

[6] Abdel-Nasser AH, Refaat MAK. Fascioliasis prevalences among animals and human in Upper Egypt. Journal of King Saud University (Science). 2009; 22: 15-1.

[7] Ardo MB, Aliyara YH,Lawal H. Prevalence of bovine fasciolosis in major abattiors of adamawa state, Nigeria. Bayero Journal of Pure and Applied Sciences. 2013; 6(1): 12 - 16.

[8] Megard JP. Fasciolosis in Black Africa. Paris: Merck, Sharp \& Dohme Research Development;1978.

[9] Uduak A. Incidence of Bovine Fasciolosis and its Economic Implications at Trans-madi Abattoir Port-Harcourt, Nigeria. Acta Parasitol Glob. 2014; 5: 206-209.

[10] Youssef A, Uga S. Review of parasitic zoonoses in Egypt. Trop. Med. Health. 2014; 42: 3- 4.

[11] Dahourou LD, Canésius N, Madi S, Oubri BG. Prevalence and economic losses resulting from parasitic zoonosis on swine and ruminants in Ouagadougou abattoir (Burkina Faso). Int. J. Biol. Chem. Sci. 2018; 12(5): 2226-2235.

[12] Zagare GML. Etude épidémiologique de la fasciolose bovine au BURKINA FASO [thèse de Docteur Vétérinaire]. Faculté de médecine et de pharmacie de DAKAR. Ecole Inter-Etats des Sciences et Médecine vétérinaries, Université Cheikh Anta Diop de Dakar; 1992.

[13] Ogunrinade AF. Bovine fascioliasisis in Nigeria VI. Parasitological characteristic of field infections. Rev. Méd. Vét. Pays Trop. 1984; 37(3): 299-303.

[14] Fontès J, Guinko S. Carte de la végétation et du sol du Burkina Faso. Notice explicative. Toulouse, France: Ministère de la coopération française, Projet Campus; 1995.

[15] Le Net J-L, Courouble F, Besognet B. Lésions hépatiques induites par Dicrocœlium dendriticum dans l'espèce bovine. In comptes Rendus des journées nationales des GTV, Nantes, mai, ph. Camuset, éditeur. 2005; 908: 2527.

[16] Benjamini Y, Yekutieli D. The control of the false discovery rate in multiple testing under dependency. The Annals of Statistics. 2001; 294: 1165-1188.

[17] Elmonir W, Mousa W, Sultan K. The prevalence of some parasitic zoonoses in different slaughtered animal species at abattoir in the mid-Delta of Egypt; with special reference to its economic implication. Alexandria J. Vet. Sci. 2015; 47: 97-103.

[18] Swai E, Ulicky E. An evaluation of the economic losses resulting from condemnation of cattle livers and loss of carcass weight due to Fasciolosis: a case study from Hai town abattoir, Kilimanjaro region, Tanzania. Livestock Res. Rural Develop. 2009; 21: 186.

[19] Khanjari A, Partovi R, Abbaszadeh S, Nemati G, Bahonar A \& Misaghi AA. Retrospective Survey of Fasciolosis and Dicrocœliosis in Slaughtered Animals in Meisam Abattoir, Tehran, Iran (2005-2008). Veterinary Research Forum. 2010; 174-178.

[20] David B, Moana P, Dayo G-K, Laurence F, Sylla S, Bolly S, Sakande H, Isabelle C, Sophie T. A Comparison of Phenotypic Traits Related to Trypanotolerance in Five West African Cattle Breeds Highlights the Value of Shorthorn Taurine Breeds. PLoS One. 2015; 10,( 5) : e0126498.

[21] Pangui LJ, Salifou S, Samb F. Fasciolose bovine au Bénin : Note préliminaire sur l'incidence de cette maladie par une enquête sérologique. Lettre circulaire ; Société Africaine de Parasitologie : U.C.A.D.Fac.de méd. N2; 1989.

[22] Mazedul I, Ripatun N. Prevalence of Fascioliasis in slaughtered Goat in Bengal Meat Abattoir House and its Economic Impact on Business. Journal of chemical, biological and physical sciences. 2015; 5(3): $2684-2692$. 